\title{
Trends in HIV surveillance data in the EU/EEA, 2005 to 2014: new HIV diagnoses still increasing in men who have sex with men
}

A Pharris ${ }^{1}$, C Quinten ${ }^{1}$, L Tavoschi ${ }^{1}$, G Spiteri ${ }^{1}$, AJ Amato-Gauci ${ }^{1}$, the ECDC HIV/AIDS Surveillance Network ${ }^{2}$

1. European Centre for Disease Prevention and Control (ECDC), Stockholm, Sweden

2. The members of the network are listed at the end of the article

Correspondence: Anastasia Pharris (anastasia.pharris@ecdc.europa.eu)

Citation style for this article:

Pharris A, Quinten C, Tavoschi L, Spiteri G, Amato-Gauci A, the ECDC HIV/AIDS Surveillance Network. Trends in HIV surveillance data in the EU/EEA, 2005 to 2014: new HIV diagnoses still increasing in men who have sex with men. Euro Surveill. 2015;20(47):pii=30071. DOI: http://dx.doi.org/10.2807/1560-7917. ES.2015.20.47.30071

Human immunodeficiency virus (HIV) transmission remains significant in Europe. Rates of acquired immunodeficiency syndrome (AIDS) have declined, but not in all countries. New HIV diagnoses have increased among native and foreign-born men who have sex with men. Median $\mathrm{CD}_{4}^{+} \mathrm{T}$-cell count at diagnosis has increased, but not in all groups, and late diagnosis remains common. HIV infection and AIDS can be eliminated in Europe with resolute prevention measures, early diagnosis and access to effective treatment.

Global goals to end acquired immunodeficiency syndrome (AIDS) by 2030 have been set by the Joint United Nations Programme on HIV/AIDS (UNAIDS) [1]. Despite growing evidence of effective measures to prevent human immunodeficiency virus (HIV) infections and eliminate AIDS, such as early treatment and new prevention interventions, HIV transmission continues at considerable levels in Europe [2-5]. To better understand transmission patterns and identify key populations where prevention efforts need strengthening, we analysed HIV and AIDS surveillance data for the years 2005 to 2014 [6]*. These data are reported annually by the 31 countries of the European Union and European Economic Area (EU/EEA) to a joint database for HIV/ AIDS coordinated by the European Centre for Disease Prevention and Control (ECDC) and the World Health Organization (WHO) Regional Office for Europe.

\section{HIV and AIDS diagnoses in the EU/EEA in 2014}

In 2014, 29,992 people were newly diagnosed with $\mathrm{HIV}$ in the EU/EEA, a rate of 5.9 diagnoses per 100,000 population. The majority of cases $(76.8 \%)$ were men (9.2 per 100,000 population vs 2.6 in women). This was largely driven by HIV transmission attributed to sex between men, which accounted for 12,677 (42\%) of all HIV diagnoses. A total of 9,833 cases (33\%) were attributed to heterosexual contact, 1,244 (4\%) to injecting drug use, and for 5,908 (20\%) of new diagnoses, the transmission mode was not reported or unknown. Migrant status was defined as native (born in the reporting country) or foreign-born (born outside the reporting country). We adjusted for reporting delay, defined as the time between HIV diagnosis and the report of this event, using reverse Cox proportional hazards models. Linear regression models were used to test for trends, whereby the significance level was set at 0.05 . Analysis of migrant status showed that more than one third (37\%) of cases were foreign-born. The transmission patterns and migrant status of cases varied considerably between EU/EEA countries (Figure 1).

In $2014,4,020$ persons in 30 EU/EEA countries were diagnosed with AIDS, resulting in a rate of 0.8 per 100,000 population. AIDS rates varied markedly from 0.1 in Slovakia to 8.5 in Latvia. The most common route of HIV acquisition among persons diagnosed with AIDS was heterosexual contact (1,771 cases, 44\%), while 1,130 cases $(28.1 \%)$ were in men who have sex with men (MSM) and 588 (14.6\%) in people who inject drugs (PWID). Just over one quarter (27.8\%) of those diagnosed with AIDS in 2014 were foreign-born.

\section{Trends in new HIV and AIDS diagnoses}

Among the 27 countries reporting on new HIV diagnoses and transmission consistently between 2005 and 2014 , the number and proportion of cases with known information on transmission and migrant status that were attributed to MSM increased significantly in native men from 5,319 (20\% of cases) to 6,265 (29\%) and in foreign-born men from 1,438 (6\%) to 2,783 (10\%) ( $p$ value for trend $<0.001$ and 0.005 , respectively) (Figure 2). 


\section{FIGURE 1}

Proportion of new HIV diagnoses with known mode of transmission, by country, transmission route and migration status, EU/EEA, $2014(\mathrm{n}=22,443)$

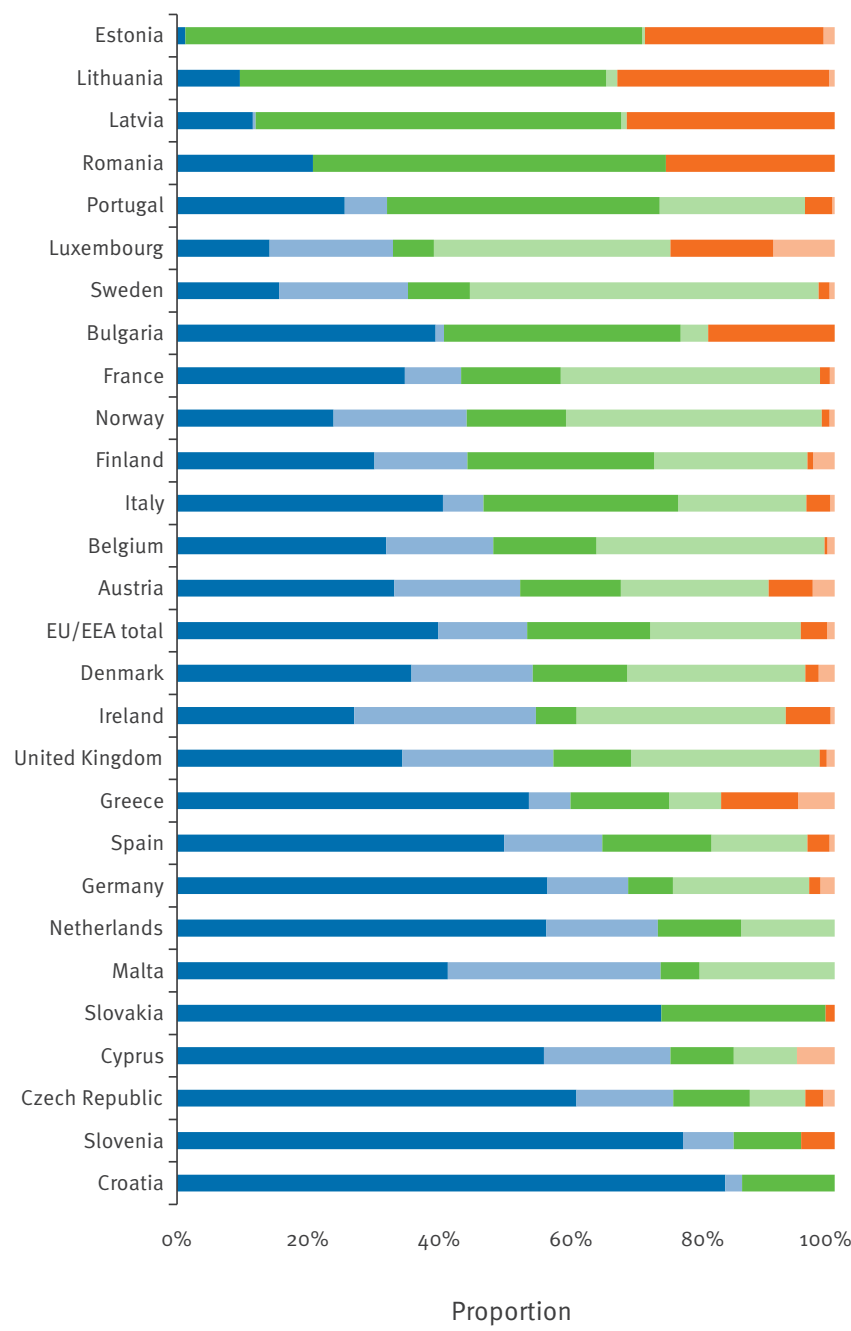

$$
\begin{array}{ll}
\text { MSM (native) } & \text { Heterosexual (foreign-born) } \\
\text { MSM (foreign-born) } & \text { PWID (native) } \\
\text { Heterosexual (native) } & \text { PWID (foreign-born) }
\end{array}
$$

EU/EEA: European Union and European Economic Area; HIV: human immunodeficiency virus; MSM: men who have sex with men; PWID: people who inject drugs.

Unknown route of transmission was excluded from proportions presented here. Data from Poland and Hungary were excluded due to missing information on country of birth. Liechtenstein and Iceland reported one case each.

The proportion of cases attributed to heterosexual contact was stable among native cases, with $3,322(17 \%)$ in 2005 and $3,368(16 \%)$ in 2014 , but decreased among foreign-born cases from 7,991 cases (31\%) to 5,548 $(21 \%)$ over the same period ( $p<0.001)$. Native cases attributed to injecting drug use decreased over the period from $1,103(4.2 \%)$ to $766(2.9 \%)$ and cases in foreign-born PWID remained stable, with the exception of a slight increase in both groups in 2011 and 2012

\section{FIGURE 2}

New HIV diagnoses, by year of diagnosis, transmission and migration status, adjusted for reporting delay, EU/ EEA, 2005-2014 $(\mathrm{n}=193,761)$

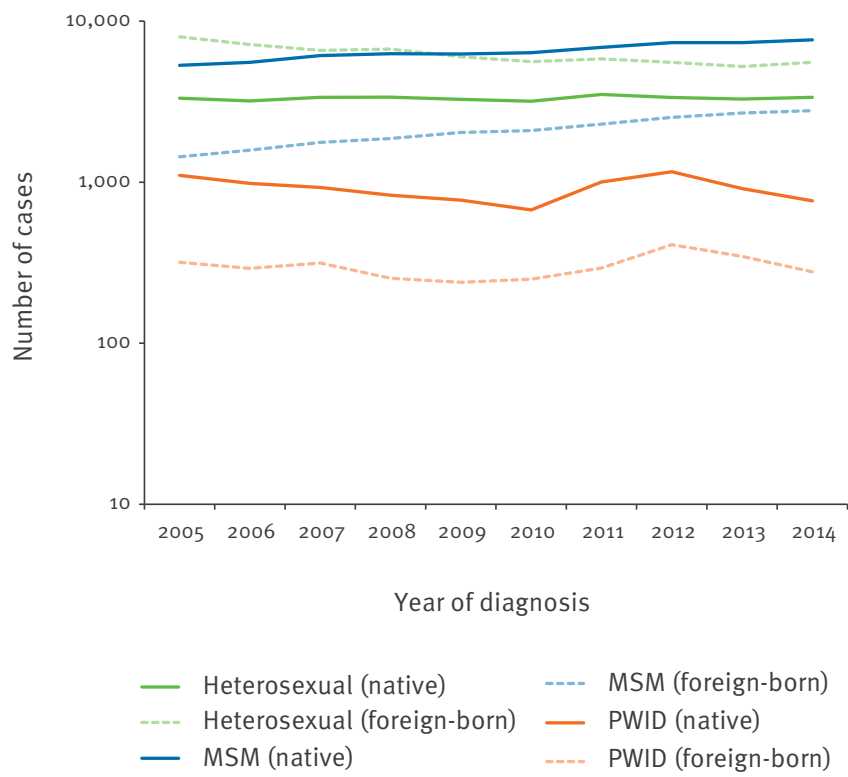

EU/EEA: European Union and European Economic Area; HIV: human immunodeficiency virus; MSM: men who have sex with men; PWID: people who inject drugs.

Logarithmic scale. Data reported by Estonia, Poland and Hungary were excluded due to incomplete reporting on transmission mode. Data from Italy and Spain were excluded due to increasing surveillance coverage during the period.

due to localised outbreaks in Athens and Bucharest (not tested for trend).

The overall rate of AIDS cases reported in the EU/EEA has halved from 2.0 per $100,000(9,203$ cases) reported in 2005 , but has increased by $50 \%$ or more since 2005 in Bulgaria, the Czech Republic, Hungary, Latvia, Lithuania and Slovenia. The number of AIDS cases has declined in all transmission groups, but most notably in native PWID ( $p<0.001)$ and MSM ( $p<0.001)$ and in native and foreign-born persons infected heterosexually ( $p<0.001$ for both groups) (Figure 3 ).

\section{Late diagnosis and AIDS}

Twenty-two EU/EEA countries reported information on $\mathrm{CD}_{4}{ }^{+}$T-cell count $/ \mathrm{mm}^{3}$ at HIV diagnosis for 18,467 (62\%) of all cases diagnosed in 2014 . Of these, 8,606 individuals $(47 \%)$ had a $\mathrm{CD}_{4}{ }^{+} \mathrm{T}$-cell count at diagnosis of less than 350 cells $/ \mathrm{mm}^{3}$, including 5,069 (27\%) with evidence of advanced disease $\left(\mathrm{CD}_{4}^{+} \mathrm{T}\right.$-cells $\left.<200 / \mathrm{mm}^{3}\right)$ (Figure 4).

When stratifying by transmission group and migrant status, the highest proportion of people presenting at a later stage of HIV infection $\left(\mathrm{CD}_{4}{ }^{+} \mathrm{T}\right.$-cells $<350$ cells $/ \mathrm{mm}^{3}$ ) was observed in foreign-born and native PWID (63\% and 60\%, respectively) and the lowest 


\section{FIGURE 3}

New AIDS diagnoses, by transmission and migration status, EU/EEA, 2005-2014 $(\mathrm{n}=55,760)$

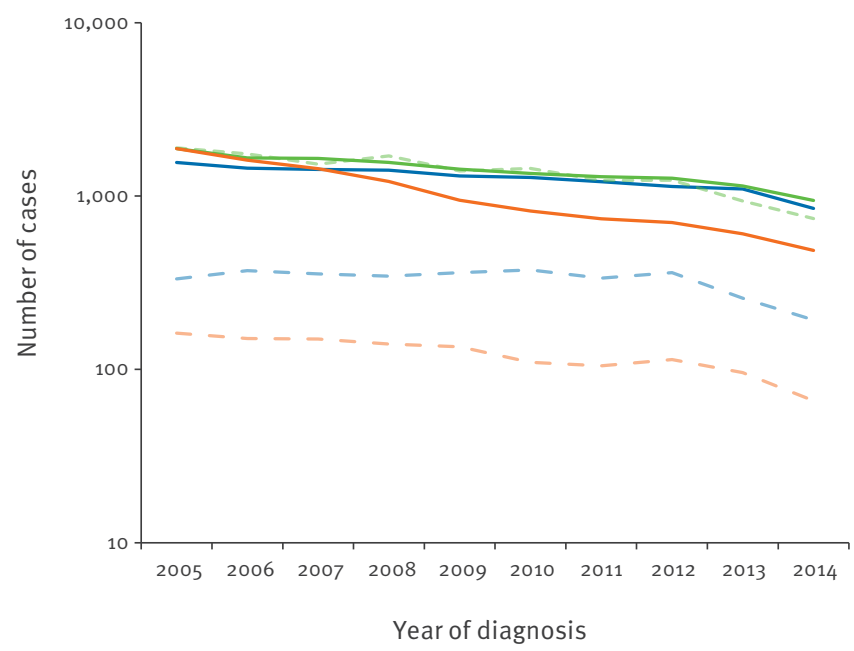

$\begin{array}{ll}- \text { MSM (native) } & -- \text { Heterosexual (migrant) } \\ --- \text { MSM (migrant) } & - \text { PWID (native) } \\ - \text { Heterosexual (native) } & --- \text { PWID (migrant) }\end{array}$

AIDS: acquired immunodeficiency syndrome; EU/EEA: European Union and European Economic Area; MSM: men who have sex with men; PWID: people who inject drugs.

Logarithmic scale. Data from Sweden were excluded due to inconsistent reporting during the period

proportion in foreign-born and native MSM (33\% and $39 \%$, respectively).

The median $\mathrm{CD}_{4}^{+} \mathrm{T}$-cell count $/ \mathrm{mm}^{3}$ by transmission group over time (Figure 5 ) increased in both native and foreign-born MSM ( $p=0.075$ and $p=0.001$, respectively) and in foreign-born heterosexuals ( $p<0.001)$, but not in native heterosexuals $(p=0.323)$. For cases who acquired HIV through drug injection, there was variation over the period, with a temporary peak in native PWID in 2011.

\section{Discussion and conclusions}

Our analysis indicates that HIV diagnoses continue to increase among native and foreign-born MSM, who represent the largest proportion of new HIV diagnoses in the EU/EEA but are diagnosed earlier than other groups. Although new diagnoses have declined in heterosexuals, influenced by a large decline in cases among foreign-born individuals, this remains the second most common transmission group in the EU/ EEA. Transmission related to injecting drug use has declined, with the exception of the outbreak reported in two countries in 2011 and 2012, however late diagnosis remains a significant problem in PWID.

At national level, the diversity of HIV epidemic patterns is apparent. Differences in the population groups

\section{FIGURE 4}

Proportion of HIV diagnoses by $\mathrm{CD}^{+} \mathrm{T}$-cell count $/ \mathrm{mm}^{3}$ category at diagnosis, all cases and by transmission mode and migration status, EU/EEA, $2014(\mathrm{n}=18,467)$

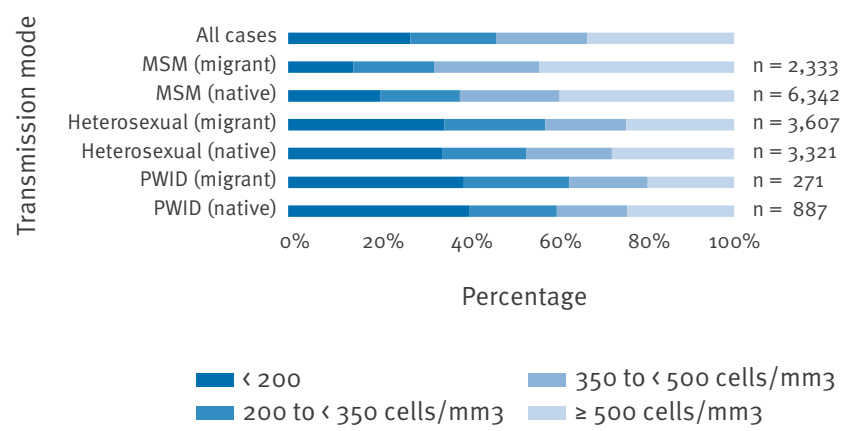

EU/EEA: European Union and European Economic Area; HIV: human immunodeficiency virus; MSM: men who have sex with men; PWID: people who inject drugs.

Data from EU/EEA countries not reporting $\mathrm{CD}_{4}{ }^{+} \mathrm{T}$-cell count at diagnosis were excluded (Croatia, Germany, Hungary, Iceland, Lithuania, Malta, Norway, Poland and Sweden). The category all cases includes 16,414 cases for whom region of origin was known, and an additional 2,053 cases for whom region of origin was unknown or not reported.

most at risk would require diversified and targeted approaches to best address particular national and sub-national variations. For countries with large, and in many cases growing, HIV epidemics in MSM, there is a pressing need to significantly scale up more effective multi-component prevention programmes based on the cornerstones of accessible and effective testing and treatment policies. They should further consider introducing new approaches to prevention, such as pre-exposure prophylaxis $[7,8]$.

Despite the decline over the last decade, migrants still constitute a considerable proportion (37\%) of new HIV diagnoses in the EU/EEA in 2014, reaching more than half in some countries. There is growing evidence that a substantial proportion of migrants, even those originating from HIV-endemic areas, acquire HIV after arrival in the EU/EEA, indicating the need for targeted interventions directed at this vulnerable population [9-12].

In all transmission categories, people continue to be diagnosed with HIV at an advanced stage of illness, particularly PWID and heterosexually acquired cases. These data suggest ongoing problems with access to, and uptake of, HIV testing in many countries [13].

Limitations to this analysis include incomplete data for some variables, particularly $\mathrm{CD}_{4}{ }^{+} \mathrm{T}$-cell count at diagnosis, transmission mode and country of birth. We addressed this by limiting the analysis to countries with more than $50 \%$ completeness of data for transmission mode and country of birth, and by performing sensitivity analysis for $\mathrm{CD}_{4}{ }^{+} \mathrm{T}$-cell trends over time by excluding countries that did not report more than $40 \%$ 


\section{FIGURE 5}

Trends in median $\mathrm{CD} 4^{+}$T-cell count $/ \mathrm{mm}^{3}$ at HIV diagnosis, by year of diagnosis, transmission group and migration status, EU/EEA, 2005-2014 $(\mathrm{n}=115,149)$

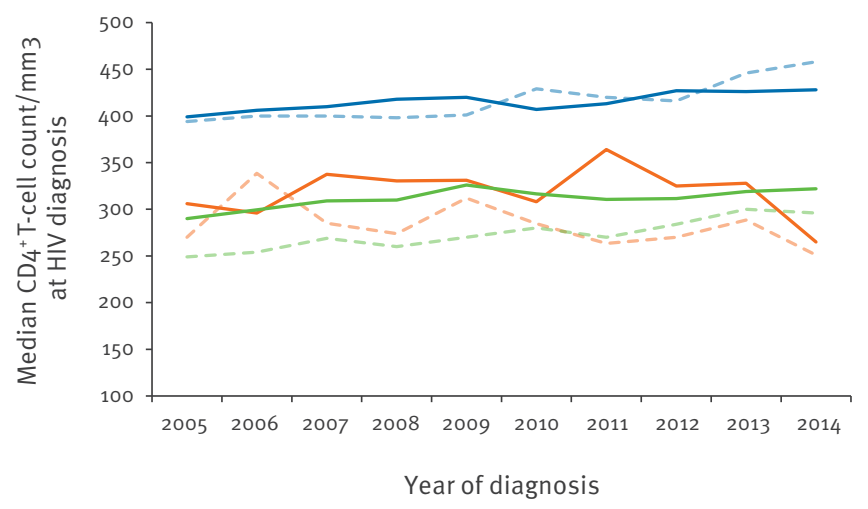

$\begin{array}{ll}- \text { MSM (native) } & -- \text { PWID (migrant) } \\ --- \text { MSM (migrant) } & - \text { Heterosexual (native) } \\ - \text { PWID (native) } & --- \text { Heterosexual (migrant) }\end{array}$

EU/EEA: European Union and European Economic Area; HIV: human immunodeficiency virus; MSM: men who have sex with men; PWID: people who inject drugs.

Logarithmic scale. Data from countries not reporting $\mathrm{CD} 4^{+} \mathrm{T}$-cell count at diagnosis were excluded (Croatia, Germany, Hungary, Iceland, Lithuania, Malta, Norway, Poland, and Sweden).

$\mathrm{CD}_{4}{ }^{+} \mathrm{T}$-cell data in each transmission group for the entire period.

HIV infection and AIDS can be eliminated in Europe with more resolute prevention measures, early HIV diagnosis and access to effective treatment [14]. The elimination of AIDS and of the high associated healthcare costs and mortality is achievable in Europe, but this will require greater investment in evidence-based HIV prevention measures, tailored to the local HIV epidemic scenario. It will further require greater attention to HIV testing, using new approaches to reach those at risk more effectively and more often.

\section{*Authors' correction}

Upon request of the authors, reference [6] was added on 10 December 2015 and all the references were renumbered.

\section{The ECDC HIV/AIDS Surveillance Network}

Austria: Daniela Schmid; Belgium: Andre Sasse, Dominique Van Beckhoven; Bulgaria: Tonka Varleva; Croatia: Tatjana Nemeth Blazic; Cyprus: Maria Koliou, Linos Hadjihannas; Czech Republic: Marek Maly; Denmark: Susan Cowan; Estonia: Kristi Rüütel; Finland: Kirsi Liitsola, Mika Salminen; France: Françoise Cazein, Josiane Pillonel, Florence Lot; Germany: Barbara Gunsenheimer-Bartmeyer; Greece: Georgios Nikolopoulos, Dimitra Paraskeva; Hungary: Maria Dudas; Iceland: Haraldur Briem, Gudrun Sigmundsdottir;
Ireland: Derval Igoe, Kate O’Donnell, Darina O'Flanagan; Italy: Barbara Suligoi; Latvia: Šarlote Konova; Lichtenstein: Sabine Erne; Lithuania: Irma Čaplinskienė; Luxembourg: Jean-Claude Schmit; Malta: Jackie Maistre Melillo, Tanya Melillo; Netherlands: Eline Op de Coul; Norway: Hans Blystad; Poland: Magdalena Rosinska; Portugal: Antonio Diniz; Romania: Mariana Mardarescu; Slovak Republic: Peter Truska; Slovenia: Irena Klavs; Spain: Mercedes Diez; Sweden: Maria Axelsson; United Kingdom: Valerie Delpech.

\section{Acknowledgements}

We would also like to thank Annemarie Stengaard from the WHO Regional Office for Europe, Marc Rondy of EpiConcept, and ECDC colleagues, especially Valentina Lazdina, Julien Beaute, Phillip Zucs, Denis Coulombier, and Mike Catchpole.

\section{Conflict of interest}

None declared.

\section{Authors' contributions}

The ECDC HIV/AIDS Surveillance network supplied the data and provided comments on the manuscript. AP developed the concept of the manuscript, analysed the data, wrote the first draft and responded to reviewers' comments. CQ conducted reporting delay adjustments and statistical tests for trend. CQ, LT, GS and AJAG contributed to the concept of the manuscript and analysis and revised the article to ensure important intellectual content. All authors have read and approved the final manuscript.

\section{References}

1. Joint United Nations Programme on HIV/AIDS (UNAIDS). Fasttrack: ending the AIDS epidemic by 2030. Geneva: UNAIDS, 2014. Available from: http://www.unaids.org/sites/default/ files/media_asset/JC2686_WAD2014report_en.pdf

2. Cohen MS, Chen YQ, McCauley M, Gamble T, Hosseinipour MC, Kumarasamy N, et al. Prevention of HIV-1 infection with early antiretroviral therapy. N Engl J Med. 2011;365(6):493-505. Available from: DOI: 10.1056/NEJMoa1105243 PMID: 21767103

3. Lundgren J, Babiker A, Gordin F, Emery S, Fätkenheuer G, Molina JM, et al. Why START? Reflections that led to the conduct of this large long-term strategic HIV trial. HIV Med. 2015;16(Suppl 1):1-9. Available from: DOI: 10.1111/hiv.12227 PMID: 25711317

4. McCormack S, Dunn DT, Desai M, Dolling DI, Gafos M, Gilson $\mathrm{R}$, et al. Pre-exposure prophylaxis to prevent the acquisition of HIV-1 infection (PROUD): effectiveness results from the pilot phase of a pragmatic open-label randomised trial. Lancet. 2015. DOI: http://dx.doi.org/10.1016/S0140-6736(15)00056-2 PMID: 26364263

5. Molina JM, Capitant C, Spire B, Pialoux G, Chidiac C, Charreau I, et al. On demand PrEP with oral TDF-FTC in MSM: Results of the ANRS Ipergay trial. Conference on Retroviruses and Opportunistic Infections (CROI); Seattle, WA; 2015.

6. European Centre for Disease Prevention and Control (ECDC), World Health Organization (WHO) Regional Office for Europe. HIV/AIDS surveillance in Europe 2014. Stockholm: ECDC; 2015. Available from: http://ecdc.europa.eu/en/publications/ Publications/hiv-aids-surveillance-in-Europe-2014.pdf

7. European Centre for Disease Prevention and Control (ECDC). HIV and STI prevention among men who have sex with men. Stockholm: ECDC; 2015. Available from: http://ecdc.europa.eu/ en/publications/Publications/hiv-sti-prevention-among-menwho-have-sex-with-men-guidance.pdf

8. Stromdahl S, Hickson F, Pharris A, Sabido M, Baral S, Thorson A. A systematic review of evidence to inform HIV prevention interventions among men who have sex with men in Europe. Euro Surveill. 2015;20(15):21096. Available from: DOI: 10.2807/1560-7917.ES2015.20.15.21096 PMID: 25953133

9. Fakoya I, Álvarez-del Arco D, Woode-Owusu M, Monge S, Rivero-Montesdeoca Y, Delpech V, et al. A systematic review of post-migration acquisition of HIV among migrants 
from countries with generalised HIV epidemics living in Europe: mplications for effectively managing HIV prevention programmes and policy. BMC Public Health. 2015;15(1):561. Available from: DOI: 10.1186/s12889-015-1852-9 PMID: 26085030

10. Hernando V, Alvárez-Del Arco D, Alejos B, Monge S, AmatoGauci AJ, Noori T, et al. HIV Infection in Migrant Populations in the European Union and European Economic Area in 2007-2012: An Epidemic on the Move. J Acquir Immune Defic Syndr. 2015;70(2):204-11. Available from: DOI: 10.1097/ QAI.0000000000000717 PMID: 26068723

11. Rice BD, Elford J, Yin Z, Delpech VC. A new method to assign country of HIV infection among heterosexuals born abroad and diagnosed with HIV.AIDS. 2012;26(15):1961-6. Available from: DOI: 10.1097/QAD.ob013e3283578b80 PMID: 22781226

12. Desgrées-du-Loû A, Pannetier J, Ravalihasy A, Gosselin A, Supervie V, Panjo H, et al. Sub-Saharan African migrants living with HIV acquired after migration, France, ANRS PARCOURS study, 2012 to 2013. Euro Surveill. 2015;20(46):30065. DOI: 10.2807/1560-7917.ES.2015.20.46.30065

13. Wilson K, Dray-Spira R, Aubrière C, Hamelin C, Spire B, Lert F; ANRS-Vespa2 Study Group. Frequency and correlates of late presentation for HIV infection in France: older adults are a risk group - results from the ANRS-VESPA2 Study, France. AIDS Care. 2014;26(sup1) Suppl 1;S83-93. DOI: http://dx.doi.org/10. 1080/09540121.2014.906554 PMID: 24731147

14. Mussini C, Antinori A, Bhagani S, Branco T, Brostrom M, Dedes N, et al. European AIDS Clinical Society Standard of Care meeting on HIV and related coinfections: The Rome Statements. HIV Med. 2015. [Epub ahead of print]. 